\title{
Persistent Depression Affects Adherence to Secondary Prevention Behaviors After Acute Coronary Syndromes
}

\author{
Ian M. Kronish, MD, ${ }^{1}$ Nina Rieckmann, PhD, ${ }^{2}$ Ethan A. Halm, MD, MPH, ${ }^{1}$ \\ Daichi Shimbo, MD, ${ }^{3}$ David Vorchheimer, MD, ${ }^{4}$ Donald C. Haas, MD, MPH, \\ Karina W. Davidson, $P h D^{3,4}$ \\ 'Division of General Internal Medicine, Mount Sinai School of Medicine, New York, NY, USA; ${ }^{2}$ Department of Psychiatry, Mount Sinai School \\ of Medicine, New York, NY, USA; ${ }^{3}$ Department of Medicine, Columbia University Medical Center, New York, NY, USA; ${ }^{4}$ Cardiovascular \\ Institute, Mount Sinai School of Medicine, New York, NY, USA.
}

\begin{abstract}
BACKGROUND: The persistence of depressive symptoms after hospitalization is a strong risk factor for mortality after acute coronary syndromes (ACS). Poor adherence to secondary prevention behaviors may be a mediator of the relationship between depression and increased mortality.
\end{abstract}

OBJECTIVE: To determine whether rates of adherence to risk reducing behaviors were affected by depressive status during hospitalization and 3 months later.

DESIGN: Prospective observational cohort study.

SETTING: Three university hospitals.

PARTICIPANTS: Five hundred and sixty patients were enrolled within 7 days after ACS. Of these, 492 (88\%) patients completed 3-month follow-up.

MEASUREMENTS: We used the Beck Depression Inventory (BDI) to assess depressive symptoms in the hospital and 3 months after discharge. We assessed adherence to 5 risk-reducing behaviors by patient self-report at 3 months. We used $\chi^{2}$ analysis to compare differences in adherence among 3 groups: persistently nondepressed (BDI $<10$ at hospitalization and 3 months); remittent depressed (BDI $\geq 10$ at hospitalization; $<10$ at 3 months); and persistently depressed patients (BDI $\geq 10$ at hospitalization and 3 months).

RESULTS: Compared with persistently nondepressed, persistently depressed patients reported lower rates of adherence to quitting smoking (adjusted odds ratio [OR] 0.23, 95\% confidence interval [95\% CI] 0.05 to 0.97), taking medications (adjusted OR 0.50, 95\% CI 0.27 to 0.95), exercising (adjusted OR 0.57, 95\% CI 0.34 to 0.95), and attending cardiac rehabilitation (adjusted OR 0.5, 95\% CI 0.27 to 0.91 ). There were no significant differences between remittent depressed and persistently nondepressed patients.

CONCLUSIONS: Persistently depressed patients were less likely to adhere to behaviors that reduce the risk of recurrent ACS. Differences in adherence to these behaviors may explain in part why depression predicts mortality after ACS.

KEY WORDS: cardiovascular diseases; depression; medication adherence; prevention; self care.

DOI: $10.1111 /$ j.1525-1497.2006.00586.x

J GEN INTERN MED 2006; 21:1178-1183.

No conflicts of interest to declare.

Presented at the National Meeting of the Society of General Internal Medicine, New Orleans, LA, May 12, 2005 and at the National Research Scholarship Awards 11th Annual Meeting, Boston, MA, June 26, 2005.

Address correspondence and requests for reprints to Dr. Davidson: Department of Medicine, Columbia University Medical Center, 622 W 168th St, PH9 Center, Room 948, New York, NY 10032 (e-mail:kd2124@columbia.edu).
$\mathrm{D}$ epressive symptoms are common after acute coronary syndromes (ACS) and occur in as many as $45 \%$ of patients during hospitalization with ACS. ${ }^{1}$ Depressive symptoms at the time of hospitalization are an independent risk factor for mortality after ACS. ${ }^{2-5}$ According to a recent meta-analysis of 7 prospective studies, depressive symptoms carry a mortality hazard ratio of 1.76 among patients with coronary artery disease after adjusting for other known risk factors. ${ }^{6}$ These findings place depression on par with other, more classic cardiac risk factors, such as high cholesterol level or hypertension. ${ }^{7,8}$

Depressive symptoms are associated with decreased adherence to recommended risk-reducing behaviors for a range of chronic illnesses, including diabetes, human immunodeficiency virus infection, and hypertension. ${ }^{9-15}$ Depressive symptoms have been associated with decreased adherence in those with coronary artery disease with respect to taking medications, attending cardiac rehabilitation, quitting smoking, exercising, and modifying diet. ${ }^{16-20}$ Prior research has shown that depressive symptoms immediately following myocardial infarction (MI) predict poor self-reported adherence to recommended behaviors 4 months after ACS. ${ }^{21}$ Poor adherence to these recommended behaviors has been proposed as a potential mediator of the relationship between depression and increased mortality in patients after ACS. ${ }^{22,23}$

Although depressive symptoms are common in the days following an ACS, these symptoms do not persist in all patients. ${ }^{1,24}$ In 1 study, up to $70 \%$ of patients remain persistently depressed 1 month after a MI. ${ }^{25}$ Depressive symptoms at the time of hospitalization may be the expression of an acute stress reaction to the cardiac event and may resolve upon returning home. However, a subset of patients remains persistently depressed after discharge from the hospital. Patients in this subset may be at higher risk for recurrent ACS than patients whose depressive symptoms remit. ${ }^{26}$ Few studies have examined the degree to which depressive symptoms persist after ACS and, to our knowledge, no studies have assessed the relationship between persistence of depression and adherence to risk reducing behaviors. ${ }^{27}$ In order to better identify patients at risk for poor adherence, it is important to know whether the persistence of depressive symptoms is related to adherence.

Manuscript received September 14, 2005

Initial editorial decision November 3, 2005

Final acceptance June 16, 2006 
We hypothesized that persistently depressed patients would have lower reported rates of adherence to recommended behaviors for prevention of recurrent ACS than persistently nondepressed patients in the 3 months after ACS. In addition, we tested whether adherence to recommended behaviors differed between persistently depressed patients and patients whose symptoms of depression remitted after 3 months.

\section{METHODS}

\section{Patients}

This was a substudy of the Coronary Psychosocial Evaluation Study (COPES), a multicenter prospective observational cohort study that examines the role of psychosocial factors in the association of depression with ACS prognosis. Patients were enrolled from coronary care and cardiac step-down units of 3 university hospitals (Mount Sinai Hospital; University of Medicine and Dentistry of New Jersey, Newark, NJ; and Yale-New Haven Hospital, New Haven, CT) between May 1, 2003 and April 15, 2005. Patients who were at least 18 years of age and were admitted with a diagnosis of acute MI or unstable angina were asked to participate. This study was approved by the Institutional Review Boards of the 3 sites.

Criteria for acute ST-segment elevation MI were the presence of ischemic chest pain lasting more than 20 minutes and ST-segment elevation of more than $1 \mathrm{~mm}$ in at least 2 contiguous leads of the electrocardiogram. Unstable angina and non-ST-segment elevation MI were defined as 1 or more symptoms from the following list: new-onset angina within 2 months, exacerbations of previous angina with pain at rest or with minimal exercise, prolonged chest pain lasting more than 20 minutes, or angina within 2 weeks following discharge for MI. In addition, patients with unstable angina or non-STsegment elevation MI had to have at least 1 of the following criteria: ischemic electrocardiographic changes, angiogram positive for coronary artery disease (CAD) on current admission, documented history of $\mathrm{CAD}$, or acute rise in serum cardiac enzymes.

Patients were eligible for inclusion if they had no terminal illness, no major deficits in cognition and no active substance abuse, if the interviews could be completed within 7 days of the initial hospitalization date, and if follow-up availability could be expected. In addition, patients had to have a total score on the Beck Depression Inventory (BDI) of $<5$ or $>9$. The BDI is a validated self-report instrument that has been used in previous studies of depression and ACS. ${ }^{28}$ Using a cutoff score of 10 , the BDI has a sensitivity of $82 \%$ and specificity of $79 \%$ for diagnosing major depression in patients diagnosed with MI. ${ }^{29}$ A score of 0 to 4 is consistent with a low-normal level of depressive symptoms and has not been associated with any increased risk for ACS recurrence. A BDI score of 5 to 9 is consistent with a high-normal level of depressive symptoms, and a BDI score of greater than 9 represents at least mild to moderate depression and has been validated as a score predictive of increased post-ACS mortality. ${ }^{4,26}$ We excluded patients with BDI scores of 5 to 9 to clearly delineate groups of patients who were depressed and nondepressed at baseline. Clinicians were not made aware of BDI results as part of this study. The assembly of the cohort is shown in Figure 1 .

\section{Assessment of Baseline Characteristics and Depression Status}

Baseline demographic and clinical variables, including the Charlson comorbidity index, were obtained at the time of enrollment by patient interview and chart abstraction. The Charlson index has been validated as a measure of risk for death in patients with chronic illness. ${ }^{30}$ The BDI was initially administered to assess symptoms of depression within 7 days of the ACS; the BDI was again administered after 3 months.

\section{Assessment of Adherence}

At 3 months, patients were also asked about their adherence to behaviors likely to be beneficial in reducing their risk for a subsequent coronary event. ${ }^{31}$ These questions included asking whether they had (1) smoked tobacco products in the last 7 days; (2) participated in a cardiac rehabilitation program; (3) exercised regularly; and (4) modified their diet to be heart healthy. Patients who reported smoking at baseline but not at 3 months were categorized as having quit smoking. Patients did not receive any specific counseling regarding these behaviors as part of the study.

In addition, patients were asked about their medication adherence using a modified Morisky scale. ${ }^{32}$ The Morisky scale is an adherence screening tool that has been validated to predict whether patients adhere to their medications. The Morisky score is calculated by assigning 1 point for each positive answer and summing them to obtain a total score between 0 and 4. Patients with a score from 0 to 1 were categorized as having good medication adherence, whereas patients with a score from 2 to 4 were categorized as having poor medication adherence. $^{32}$

\section{Statistical Analysis}

We used $\chi^{2}$ analysis to determine whether there were statistically significant differences for self-reported adherence for (1) persistently depressed (BDI $\geq 10$ at hospitalization and 3 months), compared with persistently nondepressed (BDI $<10$ at hospitalization and 3 months) and remittent depressed (BDI $\geq 10$ at hospitalization; $<10$ at 3 months) and (2) remittent depressed compared with persistently nondepressed patients. Only 16 patients completing follow-up became newly depressed at 3 months. These patients were excluded in further statistical analyses.

Multivariate logistic regression was used to calculate adjusted odds ratios (ORs) and 95\% confidence intervals (CIs) controlling simultaneously for prespecified confounders. Sociodemographic variables that had a significant univariate association with any single adherence outcome at a level of $P<.10$ were included in the multivariate model. Partner status and years of education were not included as these were collinear with whether patient lived alone and employment status, respectively. We used the Charlson index as a summary index of comorbidity. We tested analyses using individual comorbidities that had an association with either the exposure or the outcome of interest, but none changed the estimate and hence were not included in the final model. Analyses were performed using SPSS statistical software (version 13.0; SPSS Inc., Chicago, IL). 


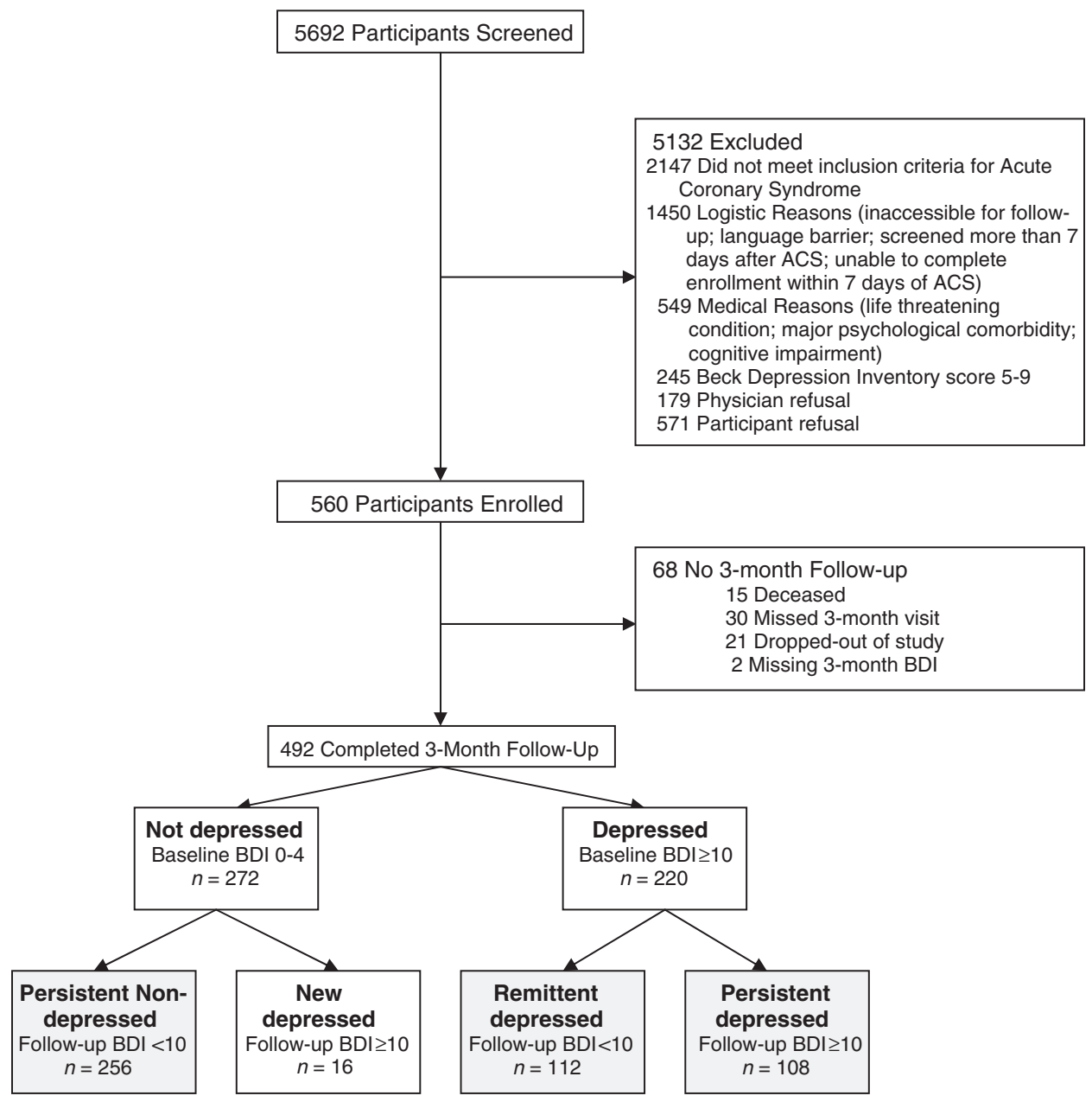

FIGURE 1. Study flowchart. ACS, acute coronary syndrome; BDI, Beck Depression Inventory.

\section{RESULTS}

\section{Characteristics}

Five thousand six hundred and ninety-two patient charts were screened (Fig. 1). Of these potentially eligible patients, $741(13.0 \%)$ were not included in the study because of physician or patient refusal. These patients differed significantly from patients that participated in the study: refusers were more likely to be Hispanic $(24.3 \%$ vs $12.5 \%$, respectively, $P=.01$ ) and older (mean age 65.2 [SD 11.9] years vs 61.5 [SD 12.2] years, respectively, $P<.001$ ) than participants. We found that patients who were lost to follow-up were more likely to have diabetes, prior congestive heart failure, higher mean Charlson score, and a lower number of years of education $(P<.05)$. Fifteen patients died during the follow-up period. When deceased patients were excluded from the group without follow-up, we found that there were no significant differences between patients who did and did not complete follow-up.

The characteristics of the study population according to depression status are summarized in Table 1 . The mean (SD) age of the cohort was $60.6(12.2)$ years. Forty-one percent of patients were women, $11 \%$ were Hispanic, and 13\% were black. The mean (SD) BDI score for patients at the time of hospitalization was 8.5 (8.6). At 3-month follow-up, the mean BDI score was $6.8(8.1)$.
Compared with persistently nondepressed patients, persistently depressed patients were more likely to be young, female, Hispanic, without a spouse or partner, unemployed, and less educated $(P<.05)$. Compared with persistently nondepressed patients, persistently depressed patients also had a higher comorbidity burden in terms of Charlson score, presence of diabetes mellitus, hypercholesterolemia, prior MI, and prior congestive heart failure. Compared with persistently nondepressed patients, remittent depressed patients were more likely to be young, female, Hispanic, without a spouse or partner, living alone, and less educated $(P<.05)$. Remittent depressed patients did not differ from persistently nondepressed patients in Charlson score or other disease variables.

\section{Self-reported Adherence Behaviors at 3 Months}

Patients' reported adherence to recommended behaviors after ACS according to their depression status are shown in Table 2. Persistently depressed patients were less likely than patients who were never depressed to report quitting smoking, taking medications regularly, exercising, and attending a cardiac rehabilitation program $(P<.05)$. Adherence did not significantly differ between patients whose symptoms of depression remitted and those who were never depressed. The 3 groups did not differ significantly with respect to whether they reported modifying their diet. 
Table 1. Characteristics of Patients by Depression Status at 3-months Follow-up

\begin{tabular}{|c|c|c|c|c|c|}
\hline Characteristic* & $\begin{array}{l}\text { Total Patients } \\
\quad(n=492)\end{array}$ & $\begin{array}{l}\text { Persistently Nondepressed } \\
\qquad(n=256)\end{array}$ & $\begin{array}{l}\text { Remittent Depressed } \\
\qquad(n=112)\end{array}$ & $\begin{array}{l}\text { Persistently Depressed } \\
\qquad(n=108)\end{array}$ & $\begin{array}{c}P \\
\text { Value }^{\dagger}\end{array}$ \\
\hline \multicolumn{6}{|l|}{ Demographic } \\
\hline Mean (SD) age, y & $60.6(12.2)$ & $62.4(11.5)$ & $59.8(12.4)$ & $57.2(12.8)$ & .001 \\
\hline Mean (SD) years of education & $13.9(3.2)$ & $14.6(3.0)$ & $13.8(3.0)$ & $12.6(3.3)$ & $<.001$ \\
\hline Female & $202(41.1)$ & $91(35.5)$ & 53 (47.3) & $53(49.1)$ & .02 \\
\hline Hispanic & 44 (8.9) & $8(3.1)$ & $15(13.4)$ & $20(18.5)$ & $<.001$ \\
\hline Black & $58(11.8)$ & $25(9.8)$ & $13(11.6)$ & $16(14.8)$ & .38 \\
\hline Lives alone & $106(21.8)$ & 44 (17.3) & $34(30.9)$ & $23(21.7)$ & .02 \\
\hline Married/partner & $318(64.6)$ & $183(71.5)$ & $67(59.8)$ & $60(55.6)$ & .006 \\
\hline Employed & $248(51.3)$ & $139(55.2)$ & $55(50.0)$ & 44 (41.9) & .07 \\
\hline \multicolumn{6}{|l|}{ Clinical } \\
\hline Smoked at baseline & 88 (17.9) & 35 (13.7) & $24(21.4)$ & $23(21.3)$ & .09 \\
\hline Hypertension & $327(67.1)$ & $165(65.2)$ & $72(64.9)$ & $78(72.9)$ & .32 \\
\hline Diabetes mellitus & $144(29.6)$ & $62(24.4)$ & 35 (31.3) & $42(40.4)$ & .01 \\
\hline Hypercholesterolemia & $330(69.9)$ & $158(64.2)$ & $79(73.1)$ & $81(79.4)$ & .01 \\
\hline Prior myocardial infarction & $115(24.8)$ & $46(19.1)$ & $30(28.6)$ & $34(33.7)$ & .01 \\
\hline Prior congestive heart failure & $31(6.4)$ & $12(4.7)$ & $5(4.6)$ & $14(13.2)$ & .008 \\
\hline Mean (SD) Charlson index & $1.3(1.5)$ & $1.1(1.3)$ & $1.3(1.5)$ & $1.7(1.7)$ & $<.001$ \\
\hline Mean (SD) BDI score, baseline & $8.5(8.6)$ & $2.0(1.4)$ & $14.0(4.2)$ & $19.1(8.1)$ & $<.001$ \\
\hline Mean (SD) BDI score, 3 mo & $6.8(8.1)$ & $2.1(2.3)$ & $5.1(2.7)$ & $18.8(8.4)$ & $<.001$ \\
\hline
\end{tabular}

*Data are presented as number (\%) of patients unless indicated otherwise. Denominators for variables vary slightly due to missing responses. Less than $5 \%$ of responses were missing.

${ }^{\dagger} \mathrm{P}-\mathrm{v}$ alue refers to overall comparisons between persistently nondepressed, remittent depressed, and persistently depressed groups. Dichotomous variables were compared using $\chi^{2}$ statistics and continuous variables using 1-way ANOVA.

\section{Multivariable Model}

We used logistic regression to determine unadjusted and adjusted odds of adhering to recommended behaviors by depression status (Table 2). In both the adjusted and unadjusted models, persistently depressed patients were more at risk of not adhering to recommended behaviors for all but one category (modified diet) as compared with persistently nondepressed patients, and adjusted ORs ranged from 0.23 to 0.57. In contrast, the adherence behaviors of remittent depressed patients were not significantly different than the adherence behaviors of persistently nondepressed patients.

\section{DISCUSSION}

In this multicenter observational cohort study of patients after ACS, we found that patients whose symptoms of depression persisted after hospitalization were at higher risk for not adhering to recommended preventive behaviors, including quitting smoking, exercising, attending cardiac rehabilitation, and taking medications regularly. Furthermore, we found that there were no statistically significant differences in adherence between patients whose symptoms of depression remitted and patients who were never depressed.

Depression is associated with poor motivation, low selfesteem, and low energy, characteristics that may be necessary for the maintenance of healthy behaviors and lifestyle changes. While it is possible that depressed patients are informed differently than nondepressed patients about the importance of secondary prevention behaviors, in our study it is unlikely that persistently depressed patients would have been informed differently than the remittent depressed group as they both started out depressed in hospital. Assuming that both remittent depressed and persistently depressed patients received equal advice from their health care providers about secondary prevention, then the lower rate of engagement in these activities by persistently depressed patients is more likely due to the effect of the persistent depressive symptoms on patients' ability to adhere to recommended behaviors.

This evidence confirms and extends previous findings that have shown that depression is a risk factor for poor adherence after ACS. Whereas previous authors have noted that depression at hospitalization is a risk factor for poor adherence 4 months later, we have shown that it is the persistence of depression that may confer this risk of poor adherence as there were no significant differences in adherence among those whose depressive symptoms remitted and those who were never depressed. ${ }^{21}$

In addition to incorporating repeated measures of depressive symptoms, another strength of our study is the diversity in the patient sample in terms of sex, race, and ethnicity, as well as the enrollment of patients from multiple hospital sites. Although there were significant differences in the socioeconomic status of our patients when analyzed by depression status, the association between depression status and adherence remained robust when we accounted for these variables.

There were several limitations of this study. First, we had a moderate rate of refusal to participate in the study among potentially eligible subjects. Patients who refuse to participate in research studies might have poorer adherence. As a result, our findings may overestimate the true rates of adherence to secondary prevention behaviors among post-ACS patients. Second, we may not have been able to account for all possible confounders. For example, we were not able to adjust for the number of medications prescribed, which some research has shown is associated with adherence. ${ }^{33}$ Similarly, some studies have shown that income correlates with poor adherence; we used employment status as a surrogate marker for income. Third, we were unable to account for the effect that identification and treatment of depressive symptoms by providers may have had on adherence. Providers, however, were not made 
Table 2. Unadjusted and Adjusted Odds Ratios for Adherence to Secondary Prevention Behaviors by Depression Status*

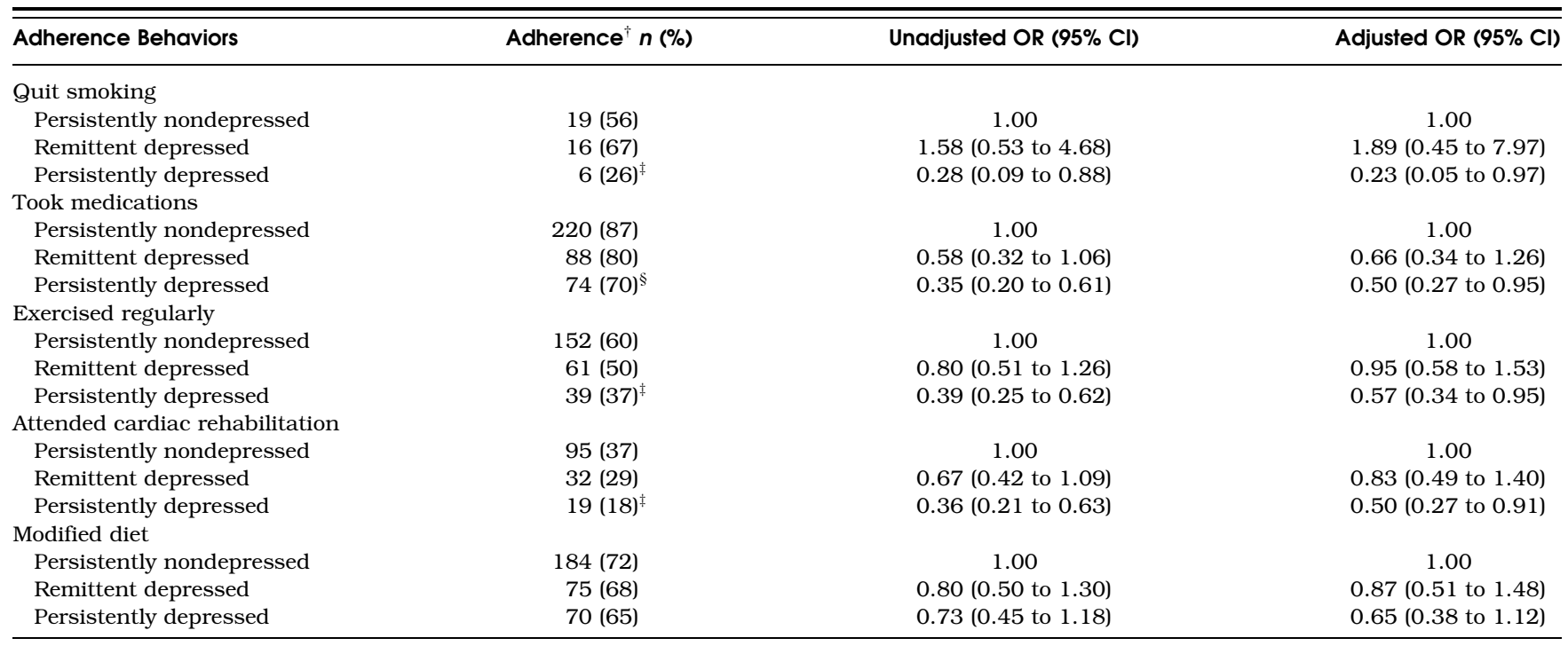

${ }^{*}$ The persistently nondepressed group was the reference group. The multivariable logistic regression model simultaneously included age, sex, race, ethnicity, whether subject lived alone, employment status, Charlson index, and depression status.

${ }^{\dagger}$ The denominators for quit smoking are based on the number of patients who were smokers at baseline $(\mathrm{n}=88)$ and differ from the other behaviors. Denominators for other behaviors vary slightly within depression groups due to missing responses but are approximately 255 for the persistently nondepressed, 112 remittent depressed and 108 persistently depressed. Less than 5\% of responses were missing.

${ }^{\ddagger}$ Adherence of the persistently depressed group was significantly different from the persistently nondepressed and remittent depressed groups $(\mathrm{P}<.05)$. ${ }^{\S}$ Adherence of the persistently depressed group was significantly different from the persistently nondepressed group $(\mathrm{P}<.05)$ but not from the remittent depressed group.

95\% CI; 95\% confidence intervals.

aware of BDI results from the study. Finally, information pertaining to adherence behaviors was primarily derived from self-report. It is possible that patients who have experienced ACS may adhere to recommended behaviors at similar levels but only report differently according to the influence of their depressive symptoms. According to some psychological studies, depressed patients may be more likely to accurately report maladaptive behaviors than their nondepressed counterparts. ${ }^{34,35}$

Our study corroborates prior research that has shown poor overall rates of adherence to healthy lifestyles after ACS. ${ }^{36,37}$ Previous studies have shown that poor adherence is associated with poorer outcomes after ACS. ${ }^{38}$ For example, in the Beta Blocker Heart Attack Trial, patients who did not adhere to the study medication after MI, whether or not the medication was placebo, were 2.6 times more likely to die within 1 year. ${ }^{39}$ This finding is consistent with the hypothesis that decreased adherence to healthy secondary prevention behaviors may be a mediator in the association of depression and mortality after ACS.

Researchers are beginning to study the effectiveness of screening for and addressing poor adherence among patients with chronic illnesses such as diabetes mellitus and heart disease. ${ }^{40}$ In some populations, such as patients with human immunodeficiency virus infection and diabetes mellitus, treatment of depression has been to shown to improve adherence. ${ }^{41,42}$ Among patients with diabetes mellitus, some trials have shown that enhanced treatment of depression can lead to improvements not only in adherence, but also in diabetic outcomes. ${ }^{43}$ Accordingly, the American Diabetes Association has added screening for mood disorders to its guidelines for standard diabetic assessments. ${ }^{44}$
Two major randomized control trials of post-ACS patients have failed to demonstrate that enhanced depression treatment can improve post-ACS outcomes. ${ }^{45,46}$ None of these trials specifically attempted to impact the adherence of patients. Future studies should assess whether enhanced screening and treatment of depressive symptoms can improve adherence in patients after ACS and whether improved adherence, in turn, can improve post-ACS mortality. These studies should also assess whether the BDI is an optimal tool for diagnosing depression in the post-ACS setting. Our study suggests that among patients who have experienced ACS, resources for screening and treating depression may be best directed at patients who are depressed at follow-up, not only in the hospital. In addition, our study suggests that it may be important to include adherence counseling as part of depression treatment programs in post-ACS patients. ${ }^{47}$

We thank Kezhen Fei, MS, and Grace Kong, BA, for their assistance with this manuscript.

This work was financially supported by Contract HC25197, and by Grants HLO76857, HLO4458, and HLO72866 from the National Heart, Lung, and Blood Institute, Bethesda, MD, and Grant 5D 14HP00163-03-00 from the Health Resources and Services Administration, Rockville, MD.

\section{REFERENCES}

1. Lane D, Carroll D, Ring C, Beevers DG, Lip GY. The prevalence and persistence of depression and anxiety following myocardial infarction. Br J Health Psychol. 2002;7:1 1-21.

2. Lesperance F, Frasure-Smith N, Juneau M, Theroux P. Depression and 1-year prognosis in unstable angina. Arch Intern Med. 2000;160:1354-60. 
3. Barefoot JC, Schroll M. Symptoms of depression, acute myocardial infarction, and total mortality in a community sample. Circulation. 1996;93:1976-80.

4. Frasure-Smith N, Lesperance F, Talajic M. Depression and 18-month prognosis after myocardial infarction. Circulation. 1995;91:999-1005.

5. Bush DE, Ziegelstein RC, Tayback M, et al. Even minimal symptoms of depression increase mortality risk after acute myocardial infarction. Am J Cardiol. 2001;88:337-41.

6. Barth J, Schumacher M, Herrmann-Lingen C. Depression as a risk factor for mortality in patients with coronary heart disease: a meta-analysis. Psychosomat Med. 2004;66:802-13.

7. Rozanski A, Blumenthal JA, Davidson KW, Saab PG, Kubzansky L. The epidemiology, pathophysiology, and management of psychosocial risk factors in cardiac practice: the emerging field of behavioral cardiology. J Am Coll Cardiol. 2005;45:637-51.

8. Wilson PW, D'Agostino RB, Levy D, Belanger AM, Silbershatz H, Kannel WB. Prediction of coronary heart disease using risk factor categories. Circulation. 1998;97:1837-47.

9. McKellar JD, Humphreys K, Piette JD. Depression increases diabetes symptoms by complicating patients' self-care adherence. Diabetes Educ. 2004;30:485-92

10. Ciechanowski PS, Katon WJ, Russo JE, Hirsch IB. The relationship of depressive symptoms to symptom reporting, self-care and glucose control in diabetes. Gen Hosp Psychiatry. 2003;25:246-52

11. DiMatteo MR, Lepper HS, Croghan TW. Depression is a risk factor for noncompliance with medical treatment: meta-analysis of the effects of anxiety and depression on patient adherence. Arch Intern Med. 2000; 160:2101-7.

12. Park H, Hong $\mathbf{Y}$, Lee H, Ha E, Sung Y. Individuals with type 2 diabetes and depressive symptoms exhibited lower adherence with self-care. $\mathrm{J}$ Clin Epidemiol. 2004;57:978-84.

13. Lin EH, Katon W, Von Korff $\mathbf{M}$, et al. Relationship of depression and diabetes self-care, medication adherence, and preventive care. Diabetes Care. 2004;27:2154-60

14. Bonnet F, Irving $\mathbf{K}$, Terra JL, Nony P, Berthezene F, Moulin P. Depressive symptoms are associated with unhealthy lifestyles in hypertensive patients with the metabolic syndrome. J Hypertens. 2005;23: 611-7.

15. Ammassari A, Antinori A, Aloisi MS, et al. Depressive symptoms, neurocognitive impairment, and adherence to highly active antiretroviral therapy among HIV-infected persons. Psychosomatics. 2004;45: 394-402.

16. Carney RM, Freedland KE, Eisen SA, Rich MW, Jaffe AS. Major depression and medication adherence in elderly patients with coronary artery disease. Health Psychol. 1995; 14:88-90.

17. Lane D, Carroll D, Ring C, Beevers DG, Lip GY. Predictors of attendance at cardiac rehabilitation after myocardial infarction. J Psychosomat Res. 2001:51:497-501.

18. Grace SL, Abbey SE, Pinto R, Shnek ZM, Irvine J, Stewart DE. Longitudinal course of depressive symptomatology after a cardiac event: effects of gender and cardiac rehabilitation. Psychosomat Med. 2005; 67:52-58.

19. Brummett BH, Babyak MA, Siegler IC, Mark DB, Williams RB, Barefoot JC. Effect of smoking and sedentary behavior on the association between depressive symptoms and mortality from coronary heart disease. Am J Cardiol. 2003;92:529-32.

20. Bonnet F, Irving $\mathbf{K}$, Terra JL, Nony P, Berthezene F, Moulin P. Anxiety and depression are associated with unhealthy lifestyle in patients at risk of cardiovascular disease. Atherosclerosis. 2005;178:339-44.

21. Ziegelstein RC, Fauerbach JA, Stevens SS, Romanelli J, Richter DP, Bush DE. Patients with depression are less likely to follow recommendations to reduce cardiac risk during recovery from a myocardial infarction. Arch Intern Med. 2000;160:1818-23.

22. Carney RM, Freedland KE, Miller GE, Jaffe AS. Depression as a risk factor for cardiac mortality and morbidity: a review of potential mechanisms. J Psychosomat Res. 2002;53:897-902.

23. Lett HS, Blumenthal JA, Babyak MA, et al. Depression as a risk factor for coronary artery disease: evidence, mechanisms, and treatment. Psychosomat Med. 2004;66:305-15.
24. Schleifer SJ, Macari-Hinson MM, Coyle DA, et al. The nature and course of depression following myocardial infarction. Arch Intern Med. 1989;149:1785-9.

25. Lauzon C, Beck CA, Huynh T, et al. Depression and prognosis following hospital admission because of acute myocardial infarction. Can Med Assoc J. 2003; 168:547-52.

26. Lesperance F, Frasure-Smith N, Talajic M, Bourassa MG. Five-year risk of cardiac mortality in relation to initial severity and one-year changes in depression symptoms after myocardial infarction. Circulation. 2002;105: 1049-53.

27. Bush DE, Ziegelstein RC, Patel UV, et al. Post-myocardial infarction depression. Evid Rep Tech Assess (Summ). 2005;123:1-8.

28. Beck AT, Steer RA. Manual for the Beck Depression Inventory. San Antonio, TX: Psychological Corporation; 1993.

29. Strik JJ, Honig A, Lousberg R, Denollet J. Sensitivity and specificity of observer and self-report questionnaires in major and minor depression following myocardial infarction. Psychosomatics. 2001;42:423-8.

30. Charlson ME, Pompei P, Ales KL, Mackenzie CR. A new method of classifying prognostic comorbidity in longitudinal studies: development and validation. J Chronic Dis. 1987;40:373-83.

31. Pignone M, Rihal CS, Bazian Ltd. Secondary prevention of ischaemic cardiac events. Clin Evid. 2004;12:193-235.

32. Morisky DE, Green LW, Levine DM. Concurrent and predictive validity of a self-reported measure of medication adherence. Med Care. 1986; 24:67-74.

33. Shalansky SJ, Levy AR. Effect of number of medications on cardiovascular therapy adherence. Ann Pharmacother. 2002;36:1532-9.

34. Morgado A, Raoux N, Jourdain G, Lecrubier Y, Widlocher D. Overreporting of maladjustment by depressed subjects: findings from retesting after recovery. Soc Psychiatry Psychiatr Epidemiol. 1991;26:68-74.

35. Watson D, Pennebaker JW. Health complaints, stress, and distress: exploring the central role of negative affectivity. Psychol Rev. 1989;96: 234-54

36. EUROASPIRE II Study Group. Lifestyle and risk factor management and use of drug therapies in coronary patients from 15 countries: principal results from EUROASPIRE II euro heart survey programme. Eur Heart J. 2001;22:554-72.

37. Eagle KA, Kline-Rogers E, Goodman SG, et al. Adherence to evidencebased therapies after discharge for acute coronary syndromes: An Ongoing Prospective, Observational Study. Am J Med. 2004;1 17:73-81.

38. DiMatteo MR, Giordain PJ, Lepper HS, Croghan TW. Patient adherence and medical treatment outcomes: a meta-analysis. Med Care. 2002;40:794-811.

39. Horwitz RI, Viscoli CM, Berkman L, et al. Treatment adherence and risk of death after a myocardial infarction. Lancet. 1990;336:542-5.

40. Rosen MI, Rigsby MO, Salahi JT, Ryan CE, Cramer JA. Electronic monitoring and counseling to improve medication adherence. Behav Res Ther. 2004;42:409-22.

41. Yun LW, Maravi M, Kobayashi JS, Barton PL, Davidson AJ. Antidepressant treatment improves adherence to antiretroviral therapy among depressed HIV-infected patients. J Acquir Immune Defic Syndr. 2005; 38:432-8.

42. Katon WJ, Von Korff $\mathbf{M}$, Lin EH, et al. The pathways study: a randomized trial of collaborative care in patients with diabetes and depression. Arch Gen Psychiatry. 2004;61:1042-9.

43. Lustman PJ, Griffith LS, Freedland KE, Kissel SS, Clouse RE. Cognitive behavior therapy for depression in type 2 diabetes mellitus: a randomized, controlled trial. Ann Intern Med. 1998;129:613-21.

44. American Diabetes Association. Standards of medical care in diabetes. Diabetes Care. 2005;28(suppl 1):S4-S36.

45. Glassman AH, O'Connor CM, Califf RM. Sertraline treatment of major depression in patients with acute MI or unstable angina. JAMA. 2002;288:701-9.

46. Berkman LF, Blumenthal J, Burg M, et al. Effects of treating depression and low perceived social support on clinical events after myocardial infarction: the enhancing recovery in coronary heart disease (ENRICHD) randomized trial. JAMA. 2004;289:3106-16.

47. Newman S. Engaging patients in managing their cardiovascular health. Heart. 2004;90(suppl 4):iv9-iv13, iv39-iv40. 